\title{
ANALISIS PENDAPATAN PETANI TAMBAK IKAN BANDENG DI KECAMATAN WOHA KABUPATEN BIMA
}

\section{INCOME ANALYSIS OF MILK FISH PONDS FARMERS IN WOHA DISTRICT, BIMA REGENCY}

\author{
Nurfadillah, Asri Hidayati, Sri Maryati \\ Fakultas Pertanian Universitas Mataram \\ srimaryati07@yahoo.com
}

\begin{abstract}
ABSTRAK
Penelitian ini bertujuan: (1) Untuk mengetahui pendapatan petani tambak ikan bandeng di Kecamatan Woha KabupatenBima. (2) Untuk mengetahui faktor-faktor yang mempengaruhi pendapatan petani tambak ikan bandeng di KecamatanWoha Kabupaten Bima.Metode penelitian ini adalah metode deskriptif dan pengumpulan data dilakukan dengan teknik survai. Unit analisis adalah petani yang mengusahakan tambak ikan bandeng di Kecamatan Woha Kabupaten Bima.Jumlah responden ditentukan sebanyak 40 orangyang terdistribusisecara proportional sampling, Selanjutnya untuk mendapatkan petani yang menjadi responden ditentukan secara insidental sampling. Data yang digunakan berupa data primer dan data sekunder yang dianalisis secara kulaitatif dan kuantitaif. Hasil penelitian menujukkan bahwa : (1) Rata-rata Pendapatan usahatani tambak ikan bandeng di Kecamatan Woha Kabupaten Bima dalam satu kali budidaya yaitu sebesar Rp 20.632.831/LLG atau sebesar Rp. 31.015.154/Ha. Dimana rata-rata biaya produksi sebesar Rp.2.415.502/ LLG atau Rp. 3.630.969/Ha dan penerimaan sebesar Rp. 23.048.333/LLG atau Rp. 34.646.123/Ha. (2) Faktor-faktor yang mempengaruhi pendapatan petani tambak ikan bandeng di Kecamatan Woha Kabupaten Bima adalah produksi, benih, luas lahan, HKO, pengalaman dan pendidikan. Yang berpengaruh nyata terhadap pendapatan petani tambak ikan bandeng adalah produksi dan HKO berdasarkan taraf nyata $0,05 \%$.
\end{abstract}

Kata kunci :Petani tambak, Ikan bandeng.

\section{ABSTRACT}

This study aims: (1) To determine the income of milkfish farmers in Woha District, Bima Regency. (2) To find out the factors that influence the income of milkfish farmers in Woha District, Bima Regency. The method of this research is descriptive method and data collection is done by survey techniques. The unit of analysis is farmers who cultivate milkfish ponds in Woha District, Bima Regency. The number of respondents was determined as many as 40 people who were distributed proportionally sampling, then to get the farmers who became respondents determined by incidental sampling. The data used is in the form of primary data and secondary data which are analyzed qualitatively and quantitatively. The results of the study show that: (1) The average income of milkfish farms in Woha Subdistrict, Bima Regency in one cultivation time is Rp 20,632,831 / LLG or Rp. 31,015,154 / Ha. Where the average production cost is Rp.2,415,502 / LLG or Rp. 3,630,969 / Ha and receipt of Rp. 23,048,333 / LLG or Rp. 34,646,123 / Ha. (2) Factors that influence the income of milkfish farmers in Woha District, Bima Regency are production, seed, land area, HKO, experience and education. The significant effect on the income of milkfish pond farmers is production and HKO based on a significance level of $0.05 \%$.

Key words: Farmers, fish, milkfish. 


\section{PENDAHULUAN}

Indonesia merupakan salah satu negara kepulauan terbesar di dunia terdiri dari gugusan pulau-pulau sebanyak 17.508 dengan luas perairan laut indonesia diperkirakan sebesar 5,8 juta km2 dan panjang garis pantai terpanjang kedua di dunia $99.093 \mathrm{~km}$, keadaan yang demikian menyebabkan Indonesia memiliki potensi yang cukup besar di bidang perikanan, mulai dari prospek pasar baik dalam negeri maupun internasional. (Kementerian Perikanan dan Kelautan 2016)

Nusa Tenggara Barat (NTB) adalah salah satu provinsi di Indonesia yang memiliki potensi budidaya ikan tambak, salah satunya adalah potensi budidaya tambak ikan bandeng yang berada di wilayah KabupatenBima. Secara keseluruhan potensi luas wilayah tambak budidaya ikan bandeng di Nusa Tenggara Barat (NTB) yaitu 7.307,23 Ha dengan jumlah produksi 13.281,46 ton yang berkembang dipulau Lombok dan pulau Sumbawa (DKP NTB 2015).

Di Kabupaten Bima tersendiri yang menjadi bagian dari daerah pengembang budidaya ikan tambak juga memiliki potensi yang tidak kalah dari daerah lainnya yang ada di Nusa Tenggara Barat, hal ini dikarenakan luas areal budidaya dan hasil dari budidaya yang terkenal yaitu ikan bandeng yang dibuat menjadi ikan bandeng presto. Khusus untuk luas potensi areal budidaya ikan bandeng di KabupatenBima adalah 5.139,80 Ha dengan luas areal pemanfaatan 497,49 Ha dengan jumlah produksi total sebesar 8.954,96 ton dengan jumlah rumah tangga perikanan (RTP) sebanyak 2.468(DKP NTB 2015)

KecamatanWoha merupakan salah satu Kecamatan yang memiliki areal tambak yang luas dan merupakan sentra produksi ikan bandeng, dimana jumlah rumah tangga (RTP) sebanyak 1049 RTP. Pada tahun 2017 luas areal tambak diKecamatanWoha adalah 1.163,41 Ha dengan jumlah produksi ikan bandeng 930,72 ton tersebar di lima desa yaitu, Desa Talabiu, Desa Penapali, Desa Dadibou, Desa Donggo Bolo, Desa Pandai. Dengan terus meningkatnya produksi tersebut maka penggunaan dan penyerapan tenaga kerja usahatani tambak ikan bandeng meningkat serta pendapatan petani maupun buruh tani akan meningkat pula (UPT Dinas Kelautan dan Perikanan KecamatanWoha KabupatenBima NTB,2017).

Dalam perkembangannya pendapatan petani tambak sulit ditentukan. Seringkali petani tambak memperoleh pendapatan tinggi, rendah dan bahkan tidak memperoleh pendapatan sama sekali. Berdasarkan uraian tersebut maka perlu untuk dilakukan penelitian mengenai "Analisis Pendapatan Petani Tambak Ikan Bandeng di Kecamatan Woha KabupatenBima". Penelitian ini bertujuan untuk : (1) Untuk mengetahui pendapatan petani tambak ikan bandeng di Kecamatan Woha Kabupaten Bima. (2) Untuk mengetahui faktorfaktor yang mempengaruhi pendapatan petani tambak ikan bandeng di Kecamatan Woha Kabupaten Bima.

\section{METODOLOGI PENELITIAN}

Metode yang digunakan dalam penelitian ini adalah metode deskriptif dengan teknik survai (Surachmat, 1994).). Sumber data dalam penelitian ini yaitu: data primer dan data sekunder. Penelitian dilakukan di Kecamatan Woha. Dari lima belas desa di Kecamatan Woha ditentukan tiga desa secara purposive sampling yaitu Desa Talabiu, Desa Donggobolo dan Desa Penapali, atas pertimbangan ketiga desa tersebut memiliki luas panen yang lebih luas dan produksi yang lebih banyak. Jumlah responden ditentukan sebanyak 40 orangyang terdistribusisecara proportional sampling. Penentuan petani yang menjadi responden ditentukan secara insidental sampling. Analisis yang digunakan dalam penelitian ini meliputi: (2) Untuk menganalisis pendapatan petani tambak ikan bandengdigunakan analisis Biaya dan Pen (Soekartawi, 2006); (3) Untuk mengetahui faktorfaktor yang mempengaruhi pendapatan petani tambak ikan bandeng.

\section{HASIL DAN PEMBAHASAN}

\section{Karakteristik Responden}

Tabel 1.Rincian Karaekteristik Responden Petani Tambak Ikan Bandeng di Kecamatan Woha Kabupaten Bima tahun 2017

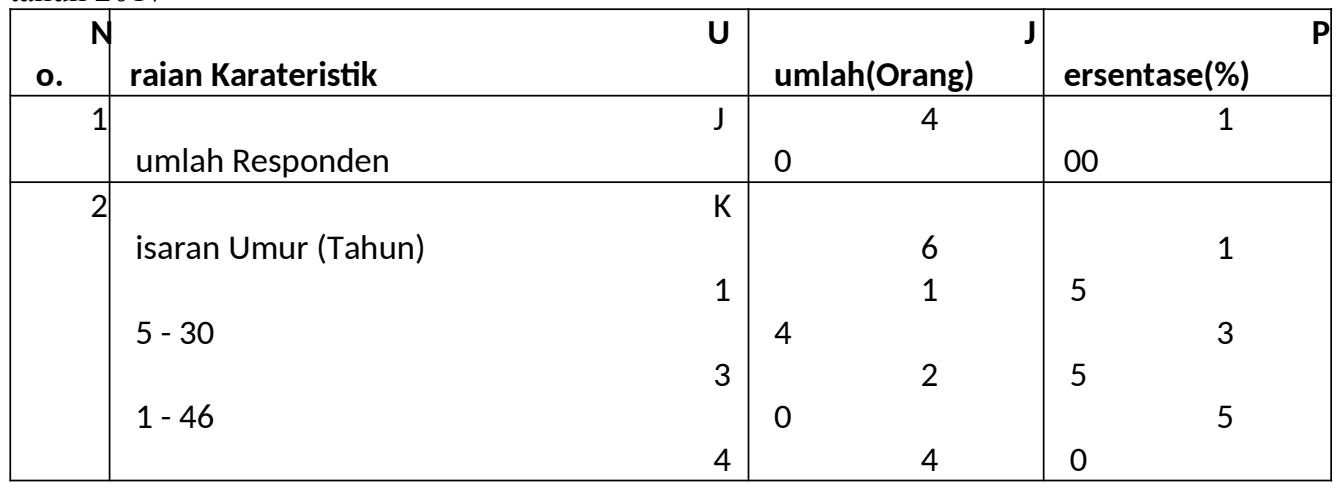




\begin{tabular}{|c|c|c|c|c|c|c|}
\hline & 7- 62 & $\mathrm{R}$ & 6 & & 00 & 1 \\
\hline 3 & $\begin{array}{l}\text { ingkat Pendidikan } \\
\text { amat Sekolah Dasar } \\
\text { idak Tamat Sekolah Dasar } \\
\text { idak Sekolah Dasar } \\
\text { ekolah Menengah Pertama } \\
\text { ekolah Menengah Atas } \\
\text { erguruan Tinggi }\end{array}$ & $\begin{array}{l}S \\
S \\
P\end{array}$ & 0 & $\begin{array}{l}9 \\
7 \\
7 \\
1 \\
1\end{array}$ & $\begin{array}{l}2,5 \\
7,5 \\
7,5 \\
5 \\
5 \\
5\end{array}$ & 1 \\
\hline 4 & $\begin{array}{l}\text { umlah Tanggungan Keluarga (Orang) } \\
-2 \\
-4 \\
-7 \\
\text { ata-rata (Orang) }\end{array}$ & $\begin{array}{l}\mathrm{J} \\
1 \\
3 \\
5 \\
\mathrm{R}\end{array}$ & $\begin{array}{l}2 \\
3\end{array}$ & $\begin{array}{l}5 \\
2\end{array}$ & $\begin{array}{l}2,5 \\
5 \\
2,5 \\
00\end{array}$ & 1 \\
\hline 5 & $\begin{array}{l}\text { engalaman Berusahatani (Tahun) } \\
-13 \\
4-24 \\
5-35 \\
\text { ata-rata (Tahun) }\end{array}$ & $\begin{array}{l} \\
3 \\
1 \\
2 \\
R\end{array}$ & $\begin{array}{l}5 \\
14 \\
1 \\
8\end{array}$ & 1 & $\begin{array}{l}7,5 \\
35 \\
7,5 \\
00\end{array}$ & 1 \\
\hline 6 & $\begin{array}{l}\text { uas Lahan Garapan }(\mathrm{Ha}) \\
1 \\
-1,40 \\
1,40 \\
\text { ata-rata }(\mathrm{Ha})\end{array}$ & $\begin{array}{l}1 \\
>\end{array}$ & $\begin{array}{l}31 \\
\text {,67 }\end{array}$ & $\begin{array}{l}7 \\
2 \\
0\end{array}$ & 7,5 & $\begin{array}{l}5 \\
1\end{array}$ \\
\hline
\end{tabular}

Sumber : Data Primer Diolah, 2018

\section{Umur Responden}

Berdasarkan Tabel 1 menunjukan bahwa kisaran umur petani responden antara 47-62 tahun memiliki jumlah yang besar yaitu sebanyak 20 orang (50\%) dan kisaran umur petani responden yang berumur antara 3146 tahun sebanyak 14 0rang (35\%). Berdasarkan kriteria penggolongan tingkat produktivitas umur, maka dapat disimpulkan bahwa umur rata-rata responden dalam penelitian ini tergolong dalam umur produktif yaitu 46 tahun.

\section{Tingkat Pendidikan Responden}


Berdasarkan Tabel 1 menunjukan bahwa rata-rata tingkat pendidikan petani responden yang tidak sekolah 9 orang $(22,5 \%)$, tidak tamat SD sebanyak 7 orang $(17,5 \%)$, tamat SD sebanyak 7 orang $(17,5 \%)$, tamat SMP sebanyak 1 orang $(2,5 \%)$, tamat SMA sebanyak 10 orang $(25 \%)$, dan tamat perguruan tinggi sebanyak 6 orang $(15 \%)$.

\section{Jumlah Anggota Keluarga}

Berdasarkan Tabel 1. dapat diketahui bahwa, jumlah tanggungan kelurga petani terbesar pada kisaran 3-4 orang dengan jumlah responden 22 orang ( $55 \%$ ) dan kisaran tanggungan keluarga terkecil ada pada kisaran $1-2$ orang dengan jumlah responden 5 orang $(12,5 \%)$. Dengan demikian dapat disimpulkan bahwa rata-rata keluarga petani tambak ikan bandeng di Kecamatan Woha Kabupaten Bima tergolong keluarga sedang pada kisaran 3-4 orang dengan jumlah responden 22 orang $(55 \%)$.

\section{Pengalaman Berusahatani}

Berdasarkan Tabel 1. menunjukan bahwa pengalaman responden dalam berusahatani tambak ikan bandeng sudah tergolong lama, hal ini ditunjukan dengan banyaknya petani yang mempunyai pengalaman antara kisaran 3-13 tahun sebanyak 15 orang (37,5\%).Pengalaman seseorang mampu mempengaruhi kemampuannya dalam mengelola dan mengembangkan kegiatan usaha yang ditekuninya.

\section{Luas Lahan Garapan}

Berdasarkan Tabel 1.. sebagian besar petani responden memiliki luas lahan yang berkisaran $<1 \mathrm{Ha}$ sebanyak 31 orang $(77,5 \%)$, petani dengan luas lahan 1-1,40 Ha sebanyak 7 orang $(17,5 \%)$, kemudian petani dengan luas lahan $>1,40$ Ha sebanyak 2 orang ( $5 \%)$.

\section{Analisis Biaya dan Pendapatan}

Untuk mengetahui besarnya pendapatan usahatani tambak ikan bandeng dilakukan dengan analisis biaya dan pendapatan. Analisis biaya dan pendapatan usahatani secara spesifik bertujuan untuk mengetahui kemampuan petani dalam mengelola biaya selama proses produksi, mulai dari persiapan lahan sampai kepada pemasaran.Rata-rata besarnya biaya produksi usahatani tambak ikan bandeng disajikan pada Tabel 2. 
Tabel 2. Rata-rata Biaya Produksi Petani Responden Usahatani Tambak ikan Bandeng di Kecamatan Woha Kabupaten Bima Tahun 2017

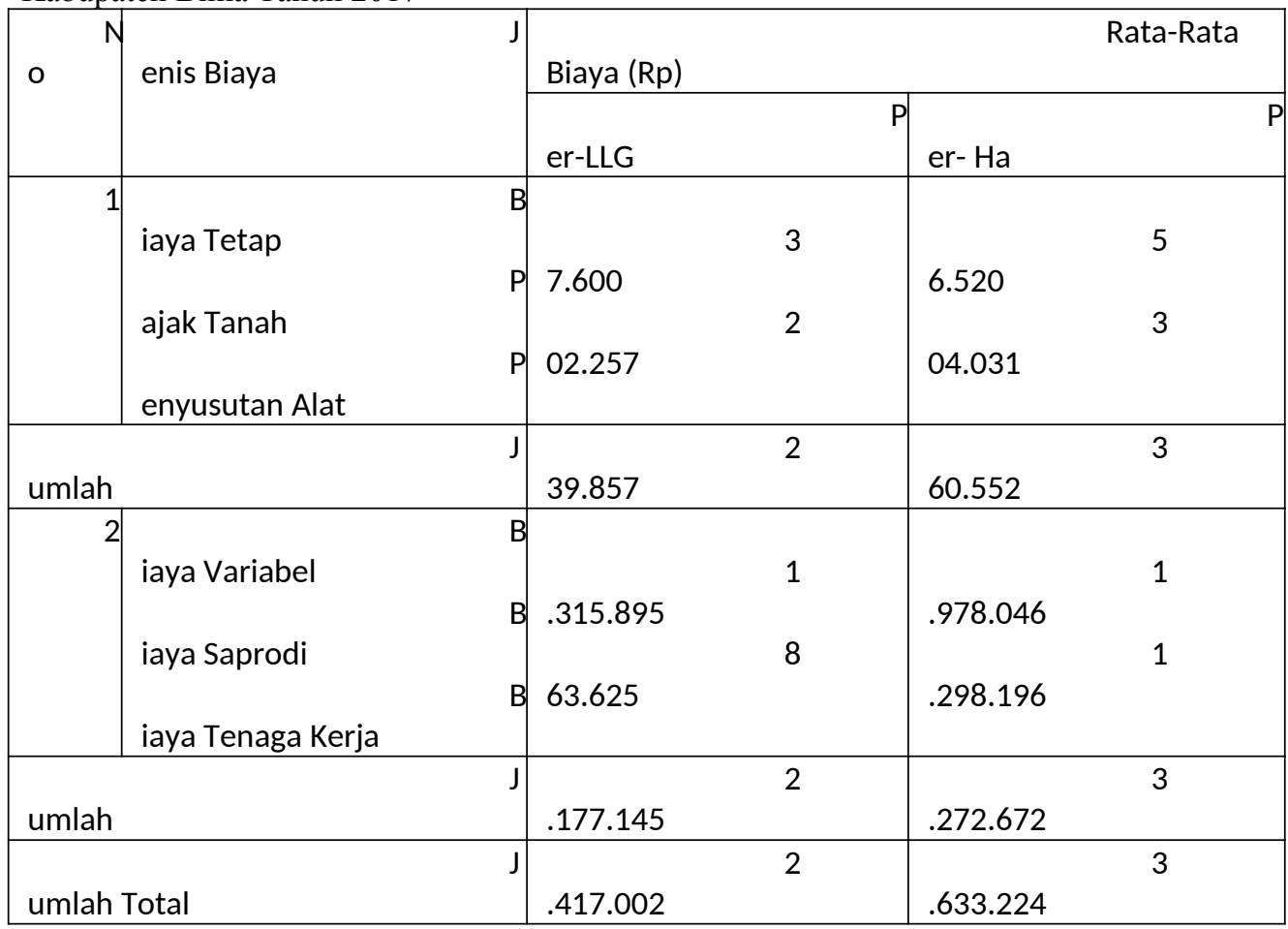

Sumber: Data Primer Diolah Tahun 2018

\section{Biaya Tetap}

Biaya tetap adalah biaya yang tidak berpengaruh langsung dengan jumlah produk atau barang yang dihasilkan oleh petani responden.Biaya tetap meliputi pajak tanah dan penyusutan alat-alat tahan lama.Rata-rata biaya penyusutan alat dapat dilihat dalam tabel 3 .

Tabel 3..Biaya Rata-Rata Penyusutan Alat Usahatani Tambak Ikan Bandeng Per Proses Produksi di Kecamatan Woha Kabupaten Bima Tahun 2017

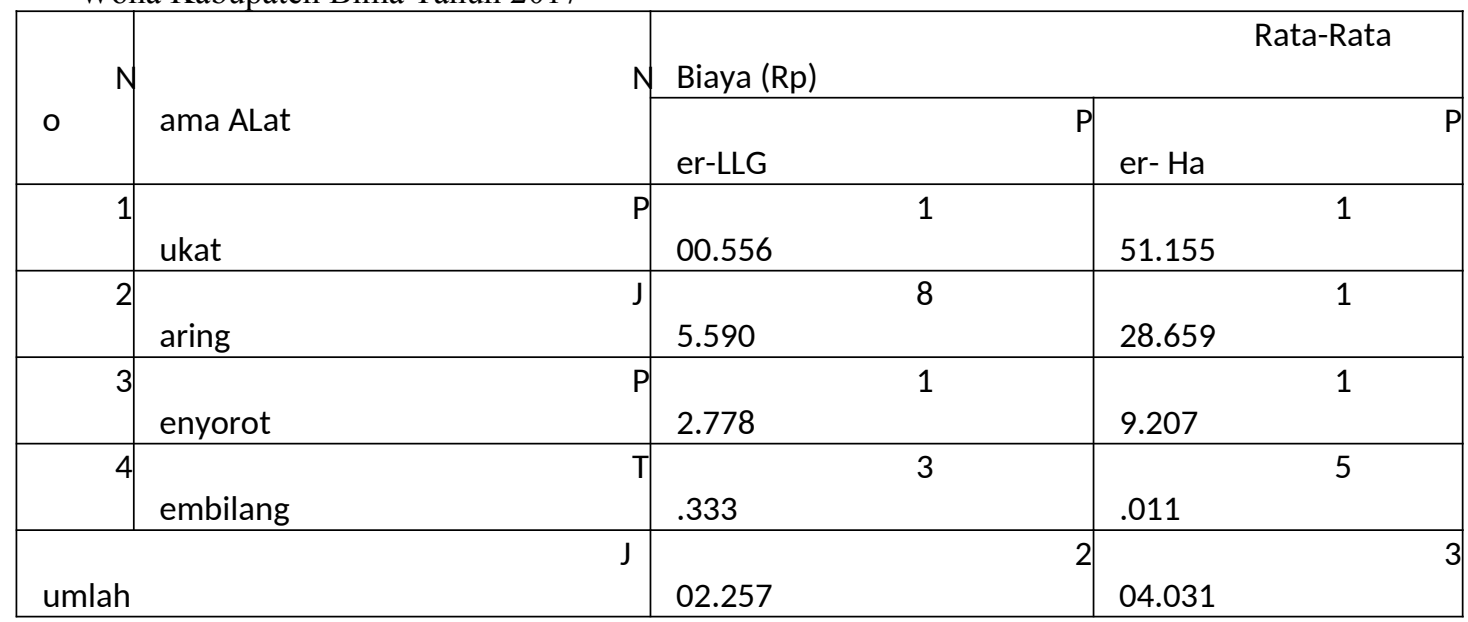

Sumber: Data Primer Diolah Tahun 2018

\section{Biaya Variabel}

Biaya variabel merupakan biaya yang dikeluarkan petani responden pada usahatani tambak ikan bandeng, yaitu besar dan kecilnya berpengaruh langsung terhadap hasil produksi.biaya variabel terdiri dari biaya sarana produksi (benih(nener), pupuk dan obat-obatan) dan biaya tenaga kerja. Rata-rata biaya sarana produksi pada usahatani tambak ikan bandeng dapat dilihat pada Tabel 4. 
Tabel 4. Rata-rata Biaya Sarana Produksi Petani Responden Usahatani Tambak Ikan Bandeng di Kecamatan Woha Kabupaten Bima 2017.

\begin{tabular}{|c|c|c|c|c|c|c|c|c|}
\hline \multirow[b]{2}{*}{0} & \multirow[b]{2}{*}{ enis Biaya } & \multirow[t]{2}{*}{$\mathrm{J}$} & \multirow[b]{2}{*}{ atuan } & \multicolumn{2}{|c|}{ umlah fisik } & \multicolumn{3}{|c|}{ ata-rata Biaya (Rp) } \\
\hline & & & & $\begin{array}{ll}\text { er-LLG } & P \\
\end{array}$ & $\begin{array}{ll} & P \\
\text { er-Ha } & \\
\end{array}$ & er-LLG & er-Ha & $P$ \\
\hline 1 & enih (nener) & B & kor & .275 & .929 & 91.250 & .189 .402 & 1 \\
\hline 2 & $\begin{array}{r}\text { Pupuk } \\
\text { - } \\
\text { - } \\
-\end{array}$ & $\begin{array}{l}\text { Urea } \\
\text { NPK } \\
\text { Organik }\end{array}$ & $\begin{array}{ll}g & K \\
g & K \\
g & K \\
\end{array}$ & $\begin{array}{ll} & 3 \\
8 & 1 \\
8 & \\
& 2 \\
4 & \\
\end{array}$ & $\begin{array}{ll}7 & 5 \\
7 & 2 \\
7 & \\
& 3 \\
6 & \\
\end{array}$ & $\begin{array}{ll}14.375 & 1 \\
3.263 & 6 \\
& 7 \\
1.400 & \\
\end{array}$ & $\begin{array}{l}71.928 \\
5.096 \\
07.328 \\
\end{array}$ & $\begin{array}{l}1 \\
9 \\
1\end{array}$ \\
\hline umlah & & $\mathrm{J}$ & & & & $49.038^{2}$ & 74.352 & 3 \\
\hline 3 & $\begin{array}{c}\text { Obat-Obatan } \\
- \\
- \\
-\end{array}$ & $\begin{array}{l}\text { Bentan } \\
\text { Samponi } \\
4 \text { Roban }\end{array}$ & $\begin{array}{ll}\mathrm{g} & \mathrm{K} \\
\mathrm{g} & \mathrm{K} \\
\text { otol } & \end{array}$ & $\begin{array}{l}2 \\
67 \\
2\end{array}$ & $\begin{array}{l}4 \\
1 \\
3\end{array}$ & $\begin{array}{ll} & 1 \\
20.000 & \\
6.483 & 8 \\
& 6 \\
9.125 & \\
\end{array}$ & $\begin{array}{l}80.383 \\
30.000 \\
03.908 \\
\end{array}$ & $\begin{array}{l}1 \\
1 \\
1\end{array}$ \\
\hline umlah & & $\mathrm{J}$ & & & & 75.608 & 14.292 & 4 \\
\hline umlar & tal & $\mathrm{J}$ & & & & $.315 .895^{1}$ & .978 .046 & 1 \\
\hline
\end{tabular}

Sumber: Data Primer Diolah Tahun 2018

\section{Biaya Tenaga Kerja}

Biaya tenaga kerja yang dimaksud dalam penelitian ini adalah biaya yang dikeluarkan petani responden usahatani tambak ikan bandeng untuk mengelola usahataninya seperti, pembersihan tambak, penebaran benih, pemupukan, pembentukan pematang, pengeringan tambak, pemasukan air dan pemanenan. Untuk lebih jelasnya biaya tenaga kerja yang dikeluarkan dapat dilihat pada Tabel 5.

Tabel 5. Biaya Rata-rata Penggunaan dan Biaya Tenaga Kerja per LLG dan per Ha Usahatani Tambak Ikan Bandeng di Kecamatan Woha Kabupaten Bima Tahun 2017.

\begin{tabular}{|c|c|c|c|c|c|c|c|c|c|c|}
\hline \multirow[b]{2}{*}{ o } & \multirow[b]{2}{*}{ enis Biaya } & \multirow[t]{2}{*}{$J$} & \multicolumn{2}{|c|}{ alam Keluarga } & \multicolumn{3}{|c|}{ uar Keluarga } & \multicolumn{3}{|c|}{ otal Biaya } \\
\hline & & & KO H & iaya & KO & iaya & $B$ & KO & iaya & $\mathrm{B}$ \\
\hline $\mathrm{I}$ & er LLG & $\mathbf{P}$ & & & & & & & & \\
\hline 1 & embersihan Tambak & $\mathrm{P}$ & ,73 & 7.000 & ,2 & 6.000 & $\begin{array}{l}6 \\
, 9 \\
\end{array}$ & 2 & 63.000 & 1 \\
\hline 2 & embentukan Pematang & $\mathrm{P}$ &, 38 & 78.125 & ,83 & 31.250 & 1 & 4 & 09,375 & 3 \\
\hline 3 & engeringan Tambak & $\mathrm{P}$ & ,79 & 6.250 &, 29 & 9.000 & $\begin{array}{l}1 \\
, 07\end{array}$ & 1 & 5.250 & 7 \\
\hline 4 & emasukan Air & $\mathrm{P}$ & ,71 & 8.500 & ,03 & .500 & 2,74 & 0 & 8.625 & 4 \\
\hline 5 & enebaran Benih & $\mathrm{P}$ & ,64 & 5.000 &, 35 & 8.750 & $\begin{array}{l}2 \\
.99\end{array}$ & 0 & 3.750 & 8 \\
\hline 6 & emupukan & $\mathrm{P}$ & ,80 & 7.500 & ,46 & 8.750 & 3 & 1 & 06.250 & 1 \\
\hline
\end{tabular}




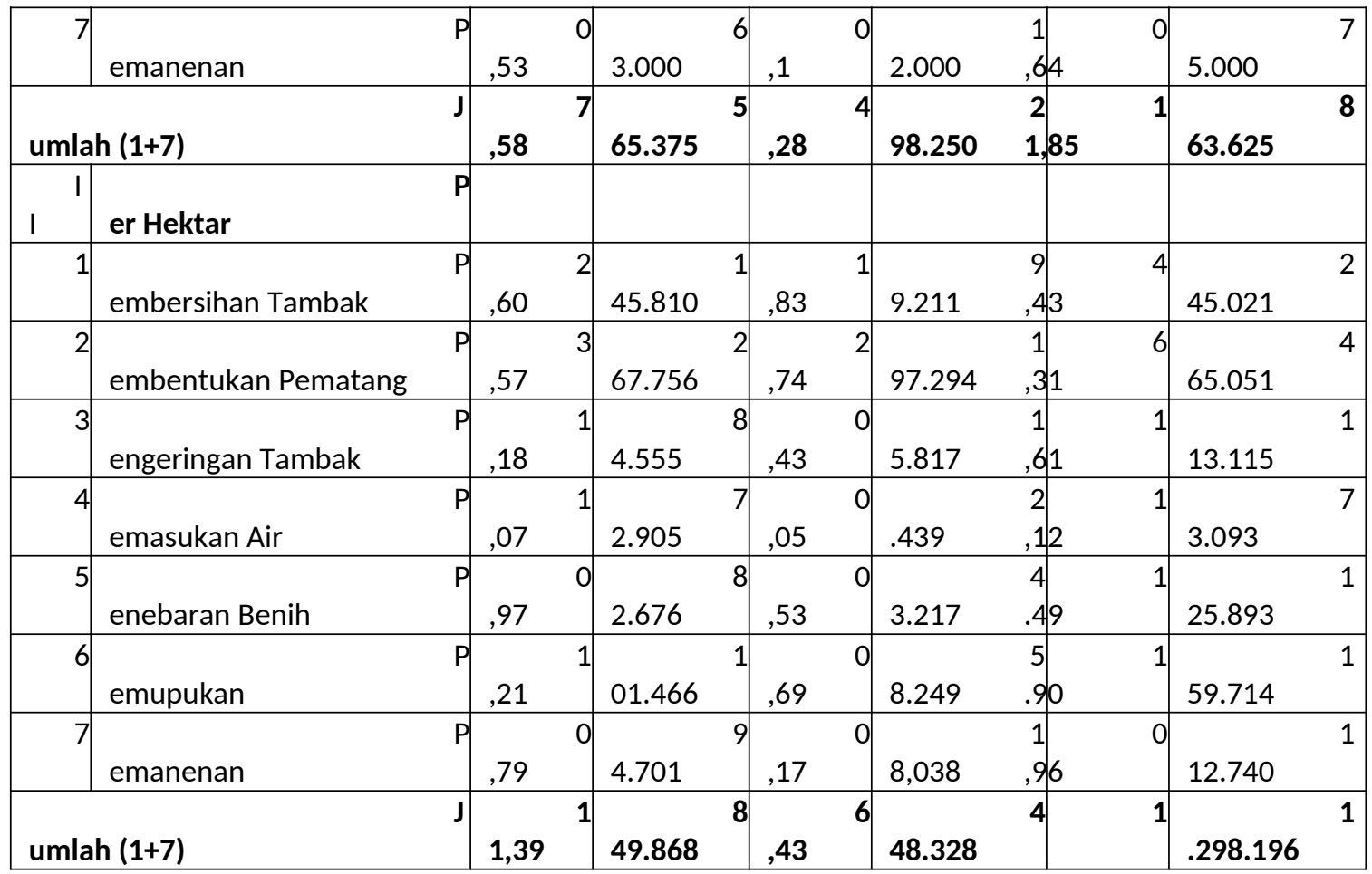

Sumber: Data Primer Diolah Tahun 2018

\section{Produksi dan Nilai Produksi}

Produksi suatu usahatani merupakan hasil perpaduan dari berbagai input produksi. Dalam penelitian ini yang dimaksud dengan produksi, yaitu ikan bandeng Sedangkan nilai produksi adalah hasil penjualan produksi ikan bandeng.Mengenai produksi dan nilai produksi dapat di lihat pada Tabel 6 .

Tabel 6. Rata-Rata Produksi, Harga, dan Nilai Produksi Tambak Ikan Bandeng di Kecamatan Woha Kabupaten Bima Tahun 2017

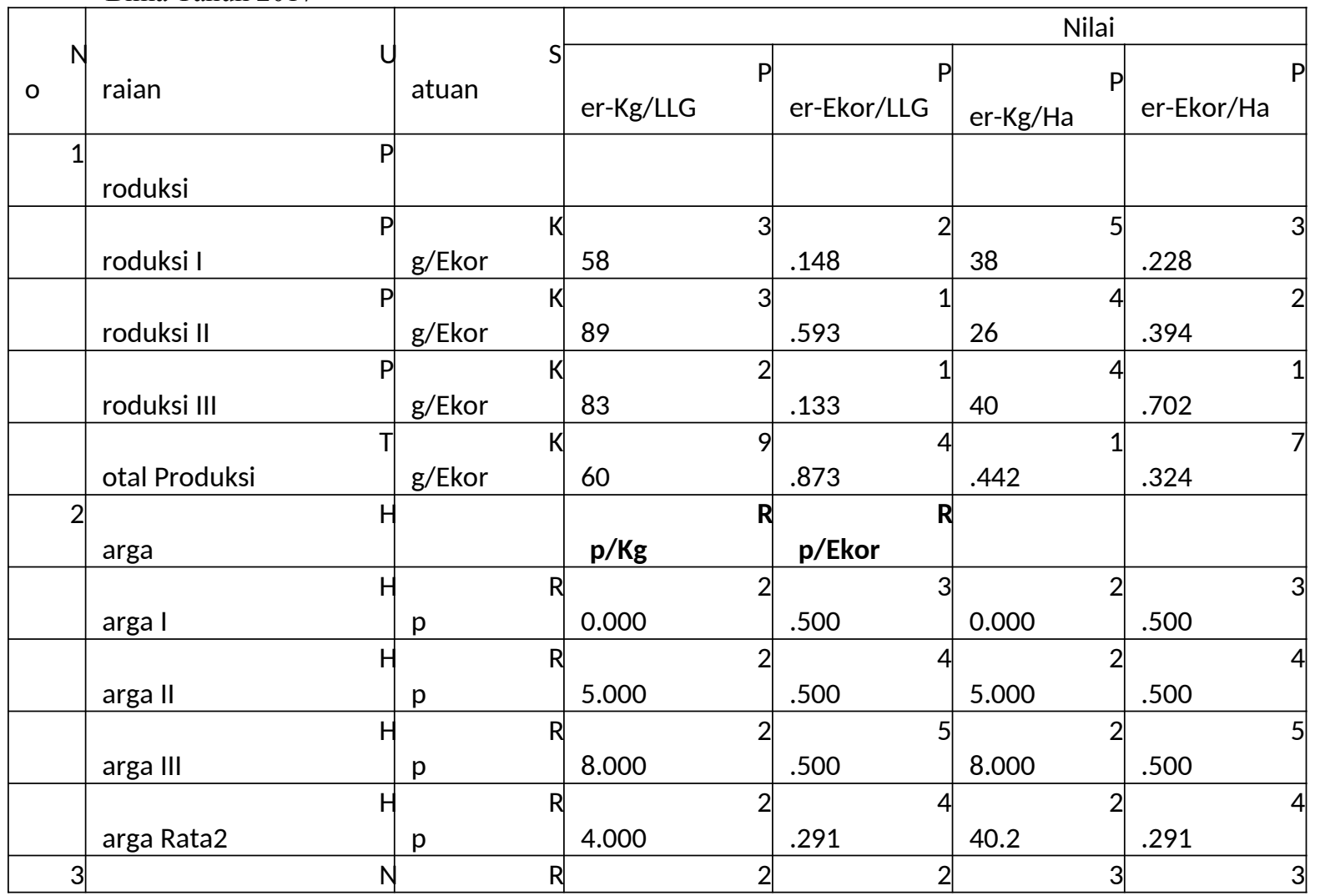




\begin{tabular}{|l|l|l|l|l|l|}
\hline ilai Produksi & $\mathrm{p}$ & 3.048 .333 & 0.911 .250 & 4.646 .123 & 1.433 .672 \\
\hline
\end{tabular}

Sumber: Data Primer Diolah Tahun 2018

\section{Pendapatan}

Pendapatan usahatani merupakan selisih antara nilai produksi dengan biaya yang dikeluarkan dalam proses produksi atau pendapatan bersih yang diperoleh dari sisa pengurangan nilai produksi dengan total biaya produksi yang dikeluarkan oleh petani pada kegiatan usahataninya. Rata-rata pendapatan usahatani tambak ikan bandeng di Kecamatan Woha Kabupaten Bima disajikan pada tabel 7.

Tabel 7. Rata-rata Pendapatan Petani Responden Usahatani Tambak Ikan Bandeng di Kecamatan Woha Kabupaten Bima Tahun 2017

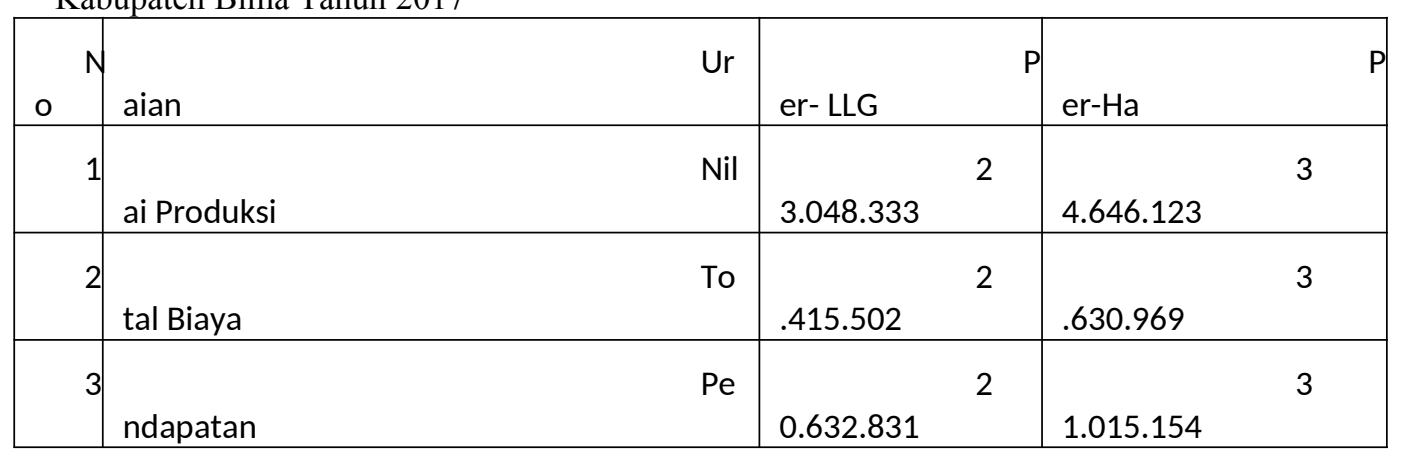

Sumber: Data Primer Diolah Tahun 2018

Berdasarkan Tabel 7. diketahui rata-rata pendapatan petani tambak ikan bandeng di Kecamatan Woha Kabupaten Bima tahun 2018 adalah sebesar Rp. 20.632.831/LLG atau sebesar Rp. 31.015.154/Ha.

Faktor-Faktor Yang Mempengaruhi Pendapatan

Faktor-faktor yang dapat mempengaruhi pendapatan petani tambak ikan bandeng di Kecamatan Woha dapat disajikan pada tabel berikut ini.

Tabel 8. Hasil Analisis Regresi Linier Faktor-Faktor Yang Mempengaruhi Pendapatan Usahatani Tambak Ikan Bandeng di Kecamatan Woha Kabupaten Bima Tahun 2017

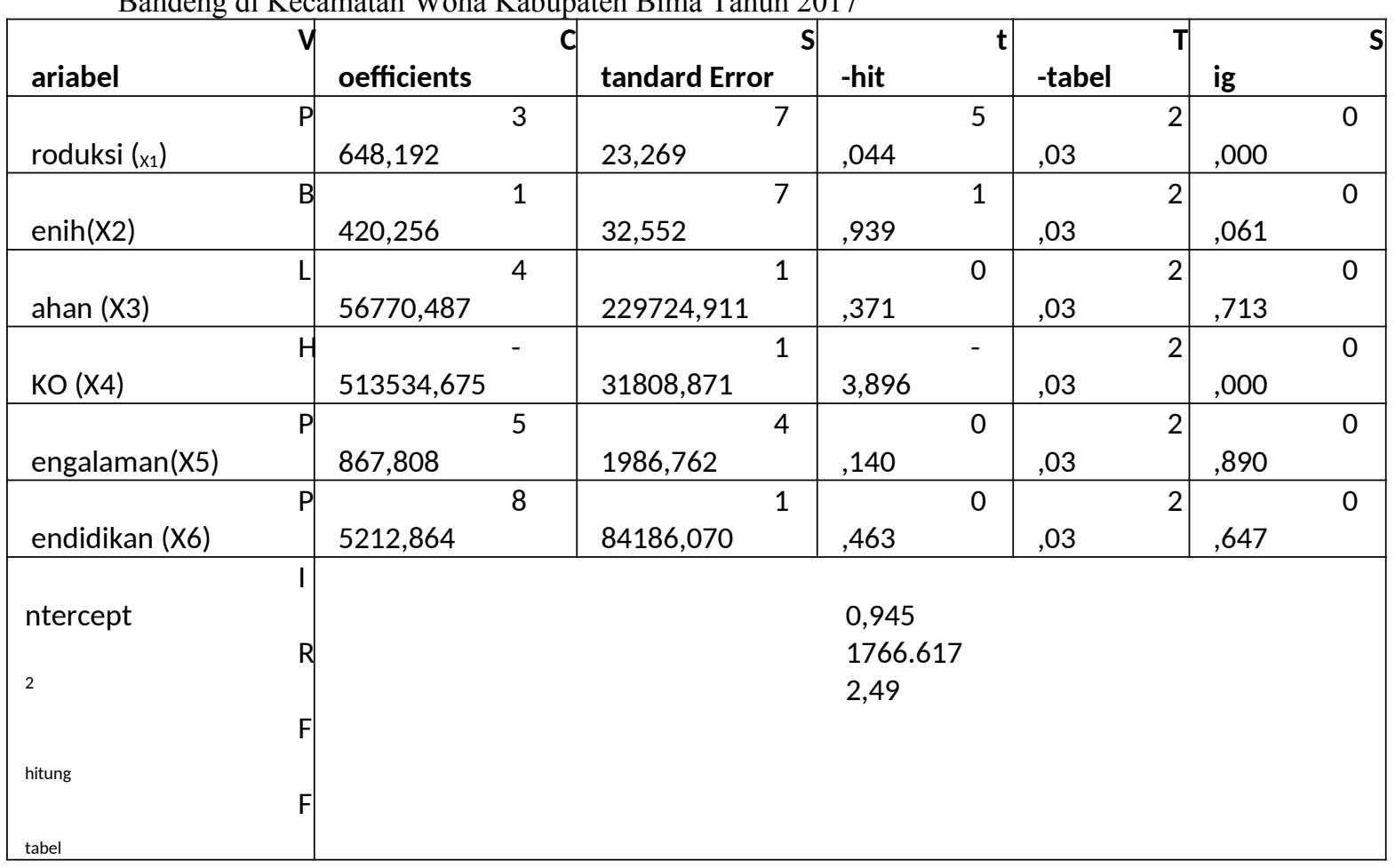

Sumber Data Primer Diolah Tahun 2018

1. Pengujian Koefisien Regresi Secara Serempak 
Dari tabel tersebut dapat diketahui secara agregat semua variabel bebas X1(produksi), X2 (benih), X3(luas lahan), X4(tenaga kerja) X5(pengalaman), X6(pendidikan). Berpengaruh nyata terhadap pendapatan petani tambak ikan bandeng, ini ditunjukan oleh hasil pengujian serempak terhadap variable bebas dengan uji $\mathrm{F}$ pada taraf nyata $5 \%$ dimana $\mathrm{F}_{\text {hitung }}$ lebih besar dari pada $\mathrm{F}_{\text {tabel }}(1766.617>2,49)$ ini menunjukan bahwa nilai koefisien (b1) secara serempak berpengaruh nyata (signifikan) atau $\mathrm{H}_{1}$ diterima. Hal ini membuktikan bahwa secara serempak variabel X1, X2, X3, X4, X5, X6 merupakan faktor yang berpengaruh terhadap pendapatan petani tambak ikan bandeng di Kecamatan Woha Kabupaten Bima

\section{Pengujian Koefisien Regresi Secara Parsial}

Berdasarkan tabel coefficients diketahui t-hitung untuk X1(produksi) sebesar 5,044 dengan nilai probabilitas 0,000 , karena nilai probabilitas lebih kecil dari $\alpha=0,05$ maka $\mathrm{H}_{0}$ ditolak, artinya koefisien regresi $\mathrm{X} 1$ signifikan atau berpengaruh nyata terhadap pendapatan (Y). Nilai t-hitung X2 sebesar 1,939 dengan probabilitas 0.061 , karena probabilits jauh lebih besar dari $\alpha=0,05$ maka $H_{\circ}$ diterima, artinya koefisien regresi $\mathrm{X}$ 2(benih) tidak signifikan atau tidak berpengaruh nyata terhadap pendapatan (Y). Nilai t-hitung X3 sebesar 0,371 dengan probabilitas 0,713 , karena probabilits jauh lebih besar dari $\alpha=0,05$ maka $\mathrm{H}_{\mathrm{o}}$ diterima, artinya koefisien regresi X3(luas lahan) tidak signifikan atau tidak berpengaruh nyata terhadap pendapatan (Y). Nilai thitung untuk X4(HKO) sebesar $-3,896$ dengan nilai probabilitas 0,000 , karena nilai probabilitas lebih kecil dari $\alpha=0,05$ maka $\mathrm{H}_{\mathrm{o}}$ ditolak, artinya koefisien regresi X4 signifikan atau berpengaruh nyata terhadap pendapatan (Y). Nilai t-hitung X5 sebesar 0,140 dengan probabilitas0,890, karena probabilits jauh lebih besar dari $\alpha=0,05$ maka $\mathrm{H}_{\mathrm{o}}$ diterima, artinya koefisien regresi X5(pengalaman) tidak signifikan atau tidak berpengaruh nyata terhadap pendapatan (Y). Nilai t-hitung X6 sebesar 0,463 dengan probabilitas 0,647, karena probabilits jauh lebih besar dari $\alpha=0,05$ maka $\mathrm{H}_{\mathrm{o}}$ diterima, artinya koefisien regresi X6(pendidikan) tidak signifikan atau tidak berpengaruh nyata terhadap pendapatan (Y).

Berdasarkan tabel coefificients dapat dituliskan persamaan regresinya

$\mathrm{Y}=912356.931+3648,192 \mathrm{X}_{1}+1420,256 \mathrm{X}_{2}+456770,487 \mathrm{X}_{3}-513534,675 \mathrm{X}_{4}+5867,808 \mathrm{X}_{5}+$ $85212,864 \mathrm{X}_{6}$

1. Konstanta sebesar Rp. 912356.931 menyatakan bahwa jika semua variabel independen dianggap konstan (tetap), maka rata-rata jumlah pendapatan petani tambak ikan bandeng sebesar Rp. $912356.931 \mathrm{~kg}$.

2. Koefisien regresi X1 sebesar Rp.3648,192 menyatakan bahwa jika variabel X1(produksi) bertambah satu kg maka akan menambah jumlah pendapatan sebesar Rp. 3648,192.

3. Koefisien regresi X2 sebesar Rp.1420,256 menyatakan bahwa jika variabel X2(benih) bertambah satu ekor maka jumlah produksi akan bertambah dan pendapatan akan meningkat sebesar Rp. 1420,256

4. Koefisien regresi X3 sebesar Rp. 456770,487 menyatakan bahwa jika variabel X3(luas lahan) bertambah satu hektar lahan yang digunakan maka akan semakin meningkat hasil produksi dan jumlah pendapatan akan meningkat sebesar Rp. 456770,487.

5. Koefisien regresi X4 sebesar Rp. - 513534,675 menyatakan bahwa jika variabel X4(HKO) bertambah satu orang maka biaya tenaga kerja yang dikeluarkan akan bertambah dan jumlah pendapatan akan berkurang sebesar Rp. $-513534,675$.

6. Koefisien regresi X5 sebesar Rp. 5867,808 menyatakan bahwa jika variabel X5(pengalaman) bertambah satu orang maka akan bertambah sebesar Rp. 5867,808 karena semakin banyak pengalamannya maka akan semakin bagus dalam pengelolaannya sehingga menghasikan produksi yang lebih banyak.

7. Koefisien regresi X6 sebesar Rp. 85212,864 menyatakan bahwa jika variabel X6(pendidikan) bertambah satu orang maka akan menambah pendapatan sebesar Rp. 85212,864 karena semakin tinggi pendidikan seseorang maka pengetahuannya lebih banyak sehingga dalam mengelola tambaknya lebih baik.

\section{KESIMPULAN DAN SARAN}

\section{Kesimpulan}

Berdasarkan hasil analisis dan pembahasan yang telah diuraikan sebelumnya, maka dapat ditarik kesimpulan sebagai berikut:

1. Rata-rata Pendapatan usahatani tambak ikan bandeng di Kecamatan Woha Kabupaten Bima dalam satu kali budidaya yaitu sebesar Rp20.632.831/LLG atau sebesar Rp.31.015.154/Ha. Dimana rata-rata biaya produksi sebesar Rp.2.415.502/ LLG atau Rp. 3.630.969/Ha dan penerimaan sebesar Rp. 23.048.333/LLG atau Rp. $34.646 .123 / \mathrm{Ha}$. 
2. Faktor-faktor yang mempengaruhi pendapatan petani tambak ikan bandeng di Kecamatan Woha Kabupaten Bima adalah produksi, benih, luas lahan, HKO, pengalaman dan pendidikan. Yang berpengaruh nyata terhadap pendapatan petani tambak ikan bandeng adalah produksi dan HKO berdasarkan taraf nyata $0,05 \%$.

Saran

Adapun saran-saran yang dapat diberikan sebagai berikut:

1. Petani tambak ikan bandeng dapat memaksimalkan produksi yang diperoleh dengan menjual panen pertama lebih sedikit dengan harga jual yang rendah sehingga untuk panen kedua dan ketiga mendapatkan harga jual yang lebih tinggi.

2. Untuk penentuan hari orang kerja, sebaiknya para pemilik usaha tambak ikan bandeng menggunakan waktunya dalam bekerja secara efisien agar dapat meningkatkan produksi usaha tambak ikan bandengnya.

\section{DAFTAR PUSTAKA}

Dinas Perikanan dan Kelautan Propinsi Nusa Tenggara Barat 2015.Luas Wilayah Keseluruhan dan Pencapain Produksi Budidaya Ikan Bandeng di Nusa Tenggara Barat 2015, Mataram.

Soekartawi,2006. Analisis Usahatani. Penerbit Universitas Indonesia (UI-Press), Jakarta.

Surachmat W, 1994. Pengantar Penelitian Ilmiah Dasar Metode Teknik. Penerbit Tarsito. Bandung $338 \mathrm{~h}$.

UPT Dinas Kelautan dan Perikanan Kecamatan Woha KabupatenBima 2017.Luas Tambak dan Produksi Ikan Bandeng di Kecamatan Woha Per Desa Tahun 2017, Bima

Nurjayanti dan Naim. 2015. Analisis Kelayakan Usahatani Tebu. Jurnal Agribisnis Vol 10, Hal 60-68. Fakultas Pertanian Universitas Wahid Hasyim Semarang. 